\title{
Editorial
}

\section{Looking Back on 2020, Looking Forward to 2021}

\author{
Gregory Y. H. Lip ${ }^{1,2}$ Anne Rigby ${ }^{3}$ Christian Weber ${ }^{3,4,5}$
}

${ }^{1}$ Liverpool Centre for Cardiovascular Science, Institute of Ageing and Chronic Disease, University of Liverpool, Liverpool, United Kingdom

${ }^{2}$ Aalborg Thrombosis Research Unit, Department of Clinical Medicine, Aalborg University, Aalborg, Denmark

3 Institute for Cardiovascular Prevention (IPEK), LMU Munich, Munich, Germany

${ }^{4}$ German Centre for Cardiovascular Research (DZHK), partner site Munich Heart Alliance, Munich, Germany

${ }^{5}$ Department of Biochemistry, Cardiovascular Research Institute Maastricht (CARIM), Maastricht University Medical Centre, Maastricht, The Netherlands

Thromb Haemost 2021;121:1-3.

We are embarking on board of 2021 with great expectations as to the ongoing scientific efforts addressing the current clinical emergency globally. In line with previous years, we offer our editorial reflections looking back on 2020, and looking forward to $2021 .^{1,2}$

Coronavirus disease (COVID-19) has unleashed an unprecedented scientific production, undoubtedly in the best interest of regaining control over the dystopic crisis. The quality of evidence published in major medical journals appeared however to be lower (e.g., according to trial criteria, database) during the first part of 2020 as compared with the same period in 2019, an effect largely due to studies related to COVID-19. A reduction in quality of published evidence represents a major concern, owing to the rapid dissemination and immediate implementation into clinical practice. Even at the highest profile journals in medicine, widely heralded publications (which we avoid to promote through citation here) warranted retraction.

Our Journal has also encountered a major shift in submissions received toward COVID-19-related studies, and a substantial share of COVID-19 publications in $2020 .^{3,4}$ We have nonetheless strived to keep our editorial requirements in mind and thoroughly privileged scientific quality over quantity, as well as international expert guidance. ${ }^{7,8}$ This is reflected by the lower general acceptance rate (under $5 \%$ ) of manuscripts relating to COVID-19 compared with the overall acceptance rate (around 20\%) in the same period. At T\&H, we indeed encourage a more traditional and balanced approach to achieve thorough and reliable results for publication.
Address for correspondence Gregory Y. H. Lip, MD, Liverpool Centre for Cardiovascular Science, University of Liverpool, William Henry Duncan Building, 6 West Derby Street, Liverpool L7 8TX, United Kingdom (e-mail: gregory.lip@liverpool.ac.uk).

Christian Weber, MD, Institute for Cardiovascular Prevention, LMU Munich, Pettenkoferstraße 9, 80336 Munich, Germany (e-mail: chweber@med.Imu.de).

In 2020, as in previous years, ${ }^{5,6}$ we could once more count on just over 900 submissions from you, a stable number reflecting the trust you place in Thrombosis and Haemostasis. In comparison to others in the field, our Impact factor has maintained a constant trend, specifically reflected by the Percentile index in the hematology and peripheral vascular disease category, which were above $80 \%$ over the past 5 years. We continue to serve as a link journal for the European Society of Cardiology Working Groups on Thrombosis and on Atherosclerosis and Vascular Biology, as well as being the official journal of the Society of Thrombosis and Hemostasis Research (GTH), the Spanish (SETH) Society on Thrombosis and Haemostasis, and the Australian Vascular Biology Society (AVBS).

\section{Reviewers}

We are very grateful to our near 900 dedicated referees as they represent the foundation of our editorial work.

We have to particularly praise our top 10 reviewers for 2020:

- Diana Gorog

- Shinichi Goto

- Stefano Barco

- Erik Klok

- José Miguel Rivera-Caravaca

- Madhumita Chatterjee

- David Jiménez

- Hugo ten Cate received

December 5, 2020

accepted

December 5, 2020 (c) 2021. Thieme. All rights reserved. Georg Thieme Verlag KG,

Rüdigerstraße 14,

70469 Stuttgart, Germany
DOI https://doi.org/

$10.1055 / \mathrm{s}-0040-1722198$ ISSN $0340-6245$. 
- Gili Kenet

- Tatjana Potpara

\section{Section Editors}

We have been very lucky to rely on the expertise and dedication from 71 section editors last year. We bid farewell to Dirk Sibbing (Germany) and thank him for these past years when we have been able to count on his dedicated expertise and look forward to future collaborations and interactions. At T\&H, we very much value diversity and inclusion and are actively engaging a diverse range of experts from across the globe.

A special thank you goes to our last year's 10 most proactive section editors:

- Job Harenberg

- Francisco Marín

- Sam Schulman

- Vera Ignjatovic

- John Eikelboom

- Jeffrey Weitz

- Francesco Violi

- Deirdre Lane

- Andreas Greinacher

- Walter Ageno

\section{What's New?}

\section{Sex in Animal Studies}

Following the good example implemented by the Arteriosclerosis, Thrombosis, and Vascular Biology Council, ${ }^{9,10}$ we set ourselves to regularly monitor sex and sex differences in animal studies published in Thrombosis and Haemostasis. In a first report published last year, ${ }^{11}$ we surveyed all preclinical studies publications from the precedent 2 years for elaborating an editorial approach regarding the requirements for documenting sex in animal studies submitted to our journal. Submission guidelines have been amended and now require systematic documentation of the sex used in preclinical studies. We are not only confident this should improve transparency and reproducibility of data published in our journal, but expect this new incentive to provide important cues to understand sex influences on cardiovascular homeostasis and disease.

\section{Accepted Manuscript Service}

We are pleased that T\&H can now offer authors and readers the possibility to publish and read manuscripts upon acceptance. This means we can now publish articles in a citable form very rapidly after acceptance, prior to final editing and typesetting. Authors have already started to embrace the new scheme and readers should soon be able to enjoy a larger breadth of $\mathrm{T} \& \mathrm{H}$ articles at once.

\section{Virtual Editorial Board Meetings}

Although virtual meetings will never replace the true and cordial face-to-face contacts we make at much missed scientific conferences, our first virtual Editorial Board Meeting allowed many of our editorial board members to "sit together" at once and led to fruitful exchange of information, suggestions, and ideas (-Fig. 1). The success and positive resonance of this new experience encourages us to plan such meetings in addition to our traditional "in flesh and blood" editorial board meeting in the future.

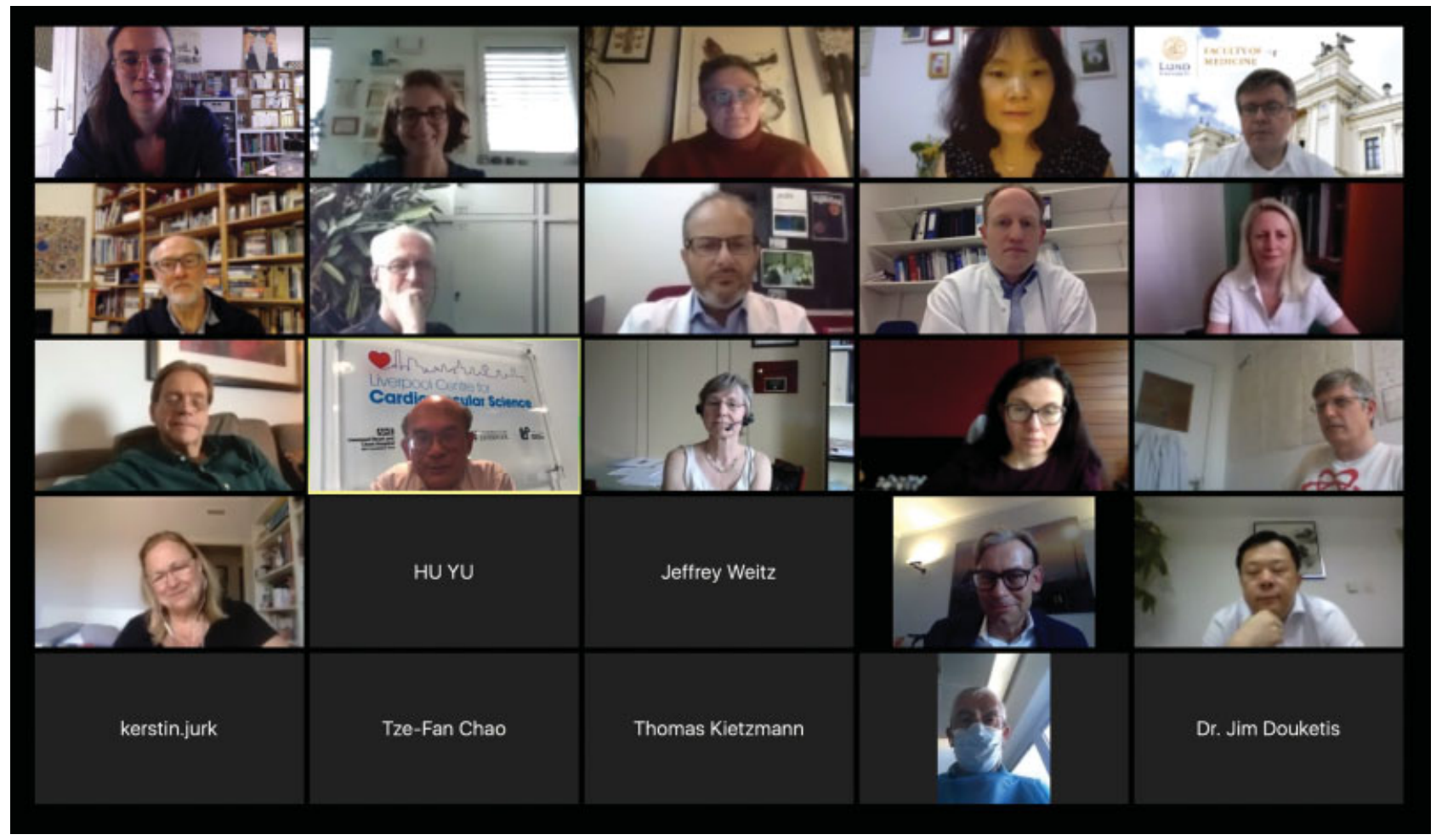

Fig. 1 Screenshot from our Virtual Editorial Board Meeting on July 17, 2020. 


\section{Social Media across the Globe}

We are happy to announce that $\mathrm{T} \& \mathrm{H}$ is now present on WeChat, China's largest social media and messaging app. We are grateful to our Section Editor Yutao Guo to have taken on the role of promoting T\&H on WeChat and are looking forward to T\&H news being disseminated throughout an even broader audience. We encourage you to pay us a visit on our social media pages and to share your work via your social media networks (have a look at our social media guide https://www.thieme. com/images/stories/PDF/Social_Media_Brochure.pdf) for best impact and reach.

Together with the entire editorial team including Elinor Switzer (Stuttgart), and Thieme Publisher (Stuttgart), we would again like to sincerely thank you, for contributing to the quality of our journal, whether it is by engaging in reading or by submitting quality investigations, as well as our section editors and reviewers, for putting their expert skills, reliability, and commitment to the service of Thrombosis and Haemostasis. We hope 2021 will be an inspiring source of clinical and scientific developments which we are looking forward to disseminating.

\section{Conflict of Interest}

G.Y.H.L. reports consultancy and speaker fees from Bayer, Bayer/Janssen, BMS/Pfizer, Biotronik, Medtronic, Boehringer Ingelheim, Microlife, Roche, and Daiichi-Sankyo outside the submitted Work. No fees received personally.

\section{References}

1 Lip GYH, Weber C. Thrombosis and Haemostasis Wishes You a Happy New Year Ahead! Thromb Haemost 2019;119(01):1-2

2 Lip GYH, Rigby A, Weber C. A Toast to the Last Decade and a Very Happy 2020 from Thrombosis and Haemostasis! Thromb Haemost 2020;120(01):1-4

3 Weber C, Rigby A, Lip GYH. Thrombosis and Haemostasis 2020 Editor's Choice Papers. Thromb Haemost 2021;121(01):109-114

4 Harenberg J, Violi F. Waves of SARS-CoV-2 infection and science in blood coagulation - a link and beyond. Thromb Haemost 2021; 121(01):4-6

5 Weber C, Lip GYH. Thrombosis and Haemostasis 2018 Editor's Choice Papers. Thromb Haemost 2019;119(01):183-186

6 Weber C, Rigby A, Lip GYH. Thrombosis and Haemostasis 2019 Editor's Choice Papers. Thromb Haemost 2020;120(01):184-190

7 Gerotziafas GT, Catalano M, Colgan MP, et al;Scientific Reviewer Committee. Guidance for the management of patients with vascular disease or cardiovascular risk factors and COVID-19: position paper from VAS-European Independent Foundation in Angiology/Vascular Medicine. Thromb Haemost 2020;120(12):1597-1628

8 Bikdeli B, Madhavan MV, Gupta A, et al;Global COVID-19 Thrombosis Collaborative Group. Pharmacological agents targeting thromboinflammation in COVID-19: review and implications for future research. Thromb Haemost 2020;120(07):1004-1024

9 Lu HS, Schmidt AM, Hegele RA, et al. Reporting sex and sex differences in preclinical studies. Arterioscler Thromb Vasc Biol 2018;38(10):e171-e184

10 Lu HS, Schmidt AM, Hegele RA, et al. Annual report on sex in preclinical studies: Arteriosclerosis, Thrombosis, and Vascular Biology publications in 2018. Arterioscler Thromb Vasc Biol 2020;40(01):e1-e9

11 Rigby A, Lip GYH, Weber C. Documenting sex and sex differences in animal studies. Thromb Haemost 2020;120(06):879-882 